\title{
In vitro Screening of Plant Extracts and Phytopharmaceuticals: Novel Approaches for the Elucidation of Active Compounds and Their Mechanisms
}

\author{
R. Gebhardt \\ Institut für Biochemie, Medizinische Fakultät, Universität Leipzig, Leipzig, Germany
}

Received: August 19, 1999; Accepted: October 16, 1999

\begin{abstract}
The advantages of cell culture systems for the screening of active compounds of plant extracts and phytopharmaceuticals are discussed and exemplified for hepatocytes and nerve cells. Recent developments and new experimental techniques allow easy access even to complex specific functions of these cells and render it possible to draw conclusions about molecular mechanisms. These in vitro approaches, therefore, may contribute essentially to the reduction of animal use in such studies. Furthermore, they may give full insight into not only the therapeutic potential but also the possible dangers of phytopharmaceuticals and may eventually lead to hints on new therapeutic fields that can be further explored.
\end{abstract}

Key words: Cell culture, hepatocytes, multi-electrode arrays, neurons, phytopharmaceuticals, reduction of animal testing, screening.

\section{Introduction}

Elucidation of active components of plant extracts as well as (phyto-)pharmaceuticals and of their mechanisms of action is a major challenge for pharmaceutical biology, pharmacology and biochemistry. In the past, model systems with either high complexity (animals, organ cultures) or low molecular organization (subcellular fractions, organ and cell homogenates) predominated this field (Fig. 1). The last decade, however, has seen an enormous trend towards isolated cellular systems, primary cells in culture and cell lines. These systems provide the desirable complexity of structurally and functionally intact cells combined with excellent experimental accessibility. Thus, they not only fill the gap in the spectrum of model systems (Fig. 1) favoring the extrapolation of experimental results, but also offer the unique possibility to elucidate interactions with vital cellular functions such as metabolism, intercellular communication, signal transduction, growth and death that were formerly difficult to address. In particular, the combination of different in vitro assay systems may not only enhance the capacity to screen for active compounds, but may also lead to better conclusions about possible mechanisms and therapeutic effects (Fig. 2). Ultimately, the results

Planta Medica 66 (2000) 99-105

(c) Georg Thieme Verlag Stuttgart · New York ISSN: 0032-0943 of these screens may provide first hints on new therapeutic fields for the respective extracts or drugs that have not been recognized before. Their potential can then be further tested both experimentally (in disease models) and clinically.

No doubt, the development of cellular screening systems currently is in an expansive state and the literature is growing exponentially. Since it is beyond the scope of this review to present an exhausting overview and because of space limitation, the focus will be on two examples, namely hepatocytes and neuronal cells, which can illustrate the design and potential of such studies.

\section{Hepatocyte Cultures as Tools for Studying Liver Functions}

Primary cultures of hepatocytes from various species including man have been shown to mimic liver functions in many respects [cf., reviews published in Cell Biol. Toxicol. Vol. 13 (4-5), 1997]. Only the maintainance of biotransformation capacity, i.e., cytochrome P450 enzymes and conjugating enzymes, may often not be sufficient, but can be considerably improved by altering the culture conditions as, for instance, by cocultivation with liver-derived cell lines $(1-3)$ or by using sandwich cultures (4) and perifusion (3), (5). Table 1 provides an overview on different functions that are influenced by natural products as well as on the respective methods for analysis.

Simple interactions of plant-derived materials with cell metabolism and biosynthetic functions can easily be detected by measuring the final product or the incorporation of a radiola-

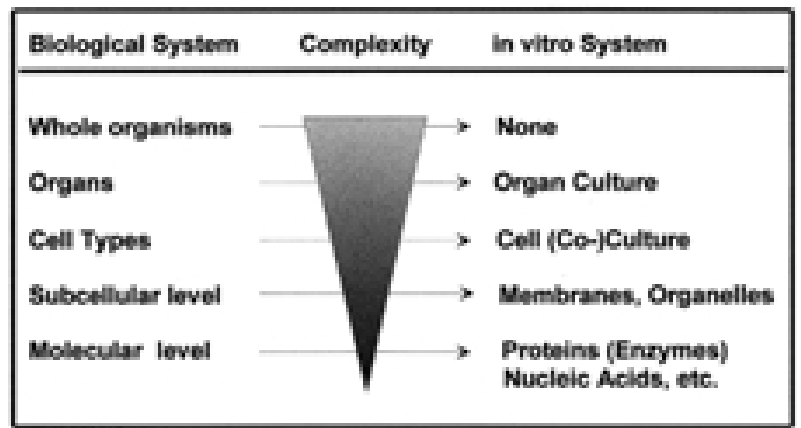

Fig. 1 Correspondence between the complexity of biological systems and different in vitro systems. 
belled precursor. This approach was successfully applied to the screening for compounds that inhibit cholesterol and/or fatty acid biosynthesis (6-9). Likewise, interference with bile acid synthesis or carbohydrate and energy metabolism was

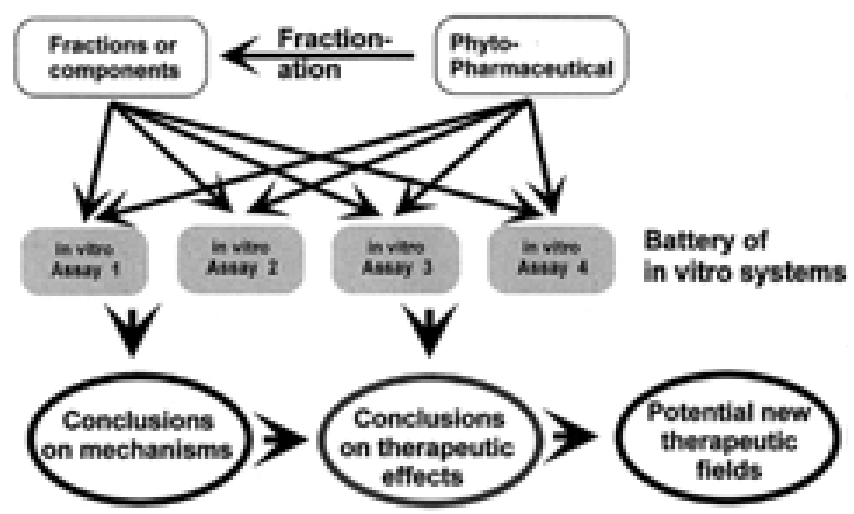

Fig. 2 Advanced strategy for in vitro screening and evaluation of efficacy of phytopharmaceuticals and their constituents. Most suitably, a battery of complementary in vitro assays is used which may be composed of different cellular systems or a combination of cellular and non-cellular assays. These allow the evaluation of the influence of plant extracts or constituents on different cellular functions and the elucidation of mechanisms of action. This approach may lead to direct conclusions about therapeutic effects and their molecular basis. In addition to the experimental support for already known beneficial effects of phytopharmaceuticals, it is possible that new interactions with cellular functions are detected that provide hints on alternative therapeutic fields. assessed (10). In general, it is helpful to measure also the influence of the materials directly on (key) enzymes of the metabolic pathways, in order to distinguish direct from indirect effects exerted through modulation of regulatory mechanisms (see below) (7), (9), (11). Furthermore, the induction as well as suppression of gene expression for enzymes and other proteins can be easily studied by various techniques (Table 1). Often, phytopharmaceuticals and drugs modulate the levels of enzymes involved in the antioxidative protection of the cells (12), (13) and of drug metabolizing enzymes (14), (15).

Interactions of drugs with cellular transport phenomena are especially interesting in liver cells, because of their involvement in the uptake and secretion of cholephilic compounds. With respect to uptake, the culture model has been used extensively in the past [for reviews, see (16), (17)]. The methods applied are usually uptake of radiolabelled compounds combined with inhibition by specific inhibitors. Transfilter well techniques (18) are especially suited for such measurements. However, the culture approach also allows for the evaluation of secretory events into preexisting (19) or newly formed bile canaliculi (16), (20). Such measurements, mainly performed with fluorescent compounds in combination with computerized image analysis (16), (19), (20), may be complemented by structural investigations using electron microscopy (21), (22). This may render it possible to study phenomena that are seen in extra- and intrahepatic cholestasis in vivo (21) and to study the influence of phytopharmaceuticals on this pathology (22).

Furthermore, interactions with elements of the cytoskeleton can be studied and easily monitored by fluorescence micro-

Table 1 Hepatocyte cultures: in vitro assay systems.

\begin{tabular}{|c|c|c|}
\hline Function & Methods & References \\
\hline Biosynthesis and Metabolism: & HPLC, Scintillation counting & \\
\hline carbohydrates & incorporation of labelled precursors & 10 \\
\hline fatty acids & incorporation of acetate & 8 \\
\hline cholesterol & incorporation of acetate, sterol pattern & $6,7,9$ \\
\hline bile acids & labelled cholesterol & \\
\hline Cellular Transport: & Uptake studies, Image analysis & \\
\hline uptake of compounds & labelled compounds & 17,18 \\
\hline biliary secretion & fluorescent compounds & 16,20 \\
\hline Stress and Toxicology: & Various methods: & \\
\hline metabolism of xenobiotics & HPLC, GC-MS & 45,23 \\
\hline oxidative stress & radicals, GSH levels, ROS & $32-34$ \\
\hline lipid peroxidation & MDA-production & 9,36 \\
\hline cytotoxicity & MTT-assay, LDH-leakage & 27,30 \\
\hline autophagy & microscopy, sequestration & 24 \\
\hline DNA damage & unscheduled DNA synthesis & 81 \\
\hline Signal transduction: & Various methods: & \\
\hline phosphorylation & antibodies, incorporation of ${ }^{32} \mathrm{P}$ & $44,46,47$ \\
\hline protein adaptors & antibodies, Western blots & \\
\hline transcription factors & Western blots, transient transfection assays & 41 \\
\hline Growth and Death: & Various methods: & \\
\hline cell proliferation & thymidine incorporation, BrdU-incorporation & 49,52 \\
\hline necrosis & LDH-leakage, propidium iodide & 25,26 \\
\hline apoptosis & annexin V/propidium iodide, electron microscopy, DNA strains & 53,54 \\
\hline
\end{tabular}


scopy or other microscopical techniques (23). This approach has also been used in combination with other techniques for demonstrating the influence of several flavonoids on hepatocyte autophagy and endocytosis (24).

Experiments on toxicology are traditionally among the most intensively performed studies (25). A variety of methods is available to assess cytotoxicity of compounds including dye uptake (26), leakage of lactate dehydrogenase (6), (26), (27), and reduction of MTT (9), (27). Metabolism of xenobiotics may be hampered by the above-mentioned problems with the cytochrome P450 system (29). Nevertheless, the interest in biotransformation is rather high, since components of phytopharmaceuticals may not only be the subjects of this process, leading to inactivation (sometimes activation) and excretion (26), (29), (30), but may in some cases severely alter the metabolic capacity for other drugs (14), (15), (30). Usually metabolites are detected by HPLC or GC-MS. In this respect, the perifusion system may be of considerable advantage, because of the steady-state determination of intermediate metabolites and kinetic constants (31).

Oxidative stress and lipid peroxidation represent another field highly relevant for natural products $(32-34)$. Many constituents of plant extracts such as flavonoids and carotinoids are potent antioxidants (35-37), but may occasionally also exert pro-oxidant actions in simple in vitro assays (38). The cellular system may distinguish whether such pro-oxidant effects are of biological importance. Furthermore, it is particularly suited to elucidate the mechanisms by which oxidative stress is prevented and its risk reduced (39), (40). Radical scavenging and/ or metal chelating activities can be studied as can the potencies to enhance the antioxidative capacity of the cells including induction of respective enzyme activities (12), (41).

An aspect brought to attention in recent years is the fact that many constituents of plant extracts interact with signal transduction. It is already well known that plant constituents, depending on their structure, occasionally act as agonists or antagonists at the level of hormone receptors (42), (43). However, it became increasingly obvious that there are many possibilities for interactions with steps of the signal transduction pathway downstream of the receptors that could lead to the modification (generation or inhibition) of the signal. Since many signal transduction pathways include the action of one or more protein kinases, these represent interesting targets for such compounds (44), (45). Through such interactions many different cellular functions may be affected, and it seems likely that this represents a major mechanism by which phytopharmaceuticals exert their effects in higher organisms. Examples include antiproliferative actions of flavonoids exerted at tyrosine kinases (46), (47), regulation of apolipoprotein B metabolism by flavanones (48), selective inhibition of NF-kappaB activation by silymarin (49), interference with the phosphorylation/dephosphorylation of HMGCoA reductase by AMP-dependent kinase (9), (11), and interactions with cytoskeletal elements through protein kinase $\mathrm{C}$ (Gebhardt, R., unpublished results).

Interference of plant-derived compounds with cell growth and death may be relevant for repair processes such as in partial hepatectomy and even more so for development of fibrosis, (viral) hepatitis, and cancer. Of course, depending on the type of pathology both stimulation or inhibition of proliferation and of apoptosis, the tissue-compatible type of cell death, may be desirable. Accordingly, screening for antiproliferative activities relevant for anticancer drugs was mainly done with hepatoma cells (15), (50). However, such screening is possible also with primary hepatocytes after stimulation by growth factors (51) and may be more appropriate to the situation in diseases other than cancer. Usually, incorporation of radiolabelled thymidine into DNA is measured (51), but determination of incorporation of BrdU and possibly immunocytochemical detection provides a good alternative (52). In many cases, particularly for flavonoids, more specific information concerning the mechanism was obtained. For instance, it was found that different steps of the cell cycle may be blocked (46), (47). Studies on apoptosis have come into focus more recently. Various techniques are used for the detection of apoptosis (53). However, it is of particular importance that the morphological criteria can be easily checked by (electron) microscopical observation in cell culture systems, since (programmed) cell death can occur in many variations (54) not necessarily expressing features like DNA laddering.

Of considerable interest are possibilities of co-cultivation of hepatocytes with other cell types (30), (55). There, important phenomena relevant to intercellular communication or to the involvement of different cell types in pathogenic mechanisms can be studied (55). Probably the best and most important example for such interactions not reviewed in detail herein is the modulation of the immune system by constituents of phytopharmaceuticals (56). However, also in the case of the liver, (abnormal) communication between different cell types may be the cause or consequence of many diseases. In culture, it is possible to disect this communication and to elucidate at which level phytopharmaceuticals may interfere. Such strategies, if properly applied for screening, may lead to the discovery of new compounds with a high therapeutic potential. Since most liver diseases cannot be adequately and efficiently treated with currently applied therapies, in vitro screening may help us to improve this unsatisfactory situation (57).

\section{Neuronal Cell Culture as Tools for Studying Brain Functions}

Cultured neurons offer excellent possibilities for studying neurotrophic effects of phytopharmaceuticals and drugs (Table 2). Besides neurons, also astrocytes may be a primary target for modulating brain function. Although the use of astrocytes was more common in the past, because they are not so difficult to isolate and culture than neurons, emphasis herein will be mainly on neurons because of space restrictions.

As listed in Table 2, normal neuronal cell cultures are suitable for analysis of general nerve functions and metabolism. Similar techniques as reviewed for hepatocytes were used to demonstrate the influence of various plant-derived extracts and compounds on basic neuronal features such as metabolism, cellular transport, ion homeostasis, survival, and proliferation (see references given in Table $\mathbf{2}$ ). There are, however, specific functions of neurons that need special attention and more sophisticated experimental systems. Such functions are coupled to activation of these cells and include interactions of neurotransmitters with cellular receptors, uptake of neurotransmitters, and particularly spike generation and synaptic activity. In the past, adequate experimental systems to ap- 
Table 2 Studies on the effects of plant-derived materials on cultured neurons.

\begin{tabular}{lll}
\hline Function & Plant-derived material & References \\
\hline $\begin{array}{l}\text { Metabolism, lon homeostasis and Activation: } \\
\text { Ca }{ }^{2+} \text { elevation }\end{array}$ & baicalin, baicalein & 66 \\
$\mathrm{Ca}^{2+}$ mobilization & sho-saiko-to, other extracts, & 68 \\
& various & 69 \\
neuronal activation & Panax ginseng extracts & 72 \\
$\quad$ excited state processes & hypericin & 74 \\
Cellular Transport: & verapamil (synthetic drug) & \\
Inhibition of P-glycoprotein & & 64 \\
(blood brain barrier model) & hypericum & \\
serotonin uptake (astrocytes) & & 58 \\
Stress and Toxicology: & epigallocatechin gallate & 67 \\
nitric oxide synthase expression & various dietary compounds & 59 \\
nitric oxide production & ricin, volkensin, & 75 \\
cytotoxicity & repin & 60 \\
excitotoxic injury & 2-deoxy-d-glucose & 71 \\
& glutamate receptor antagonists, \\
Survival, Proliferation and Apoptosis: & various & 69 \\
protection against seizure activity & kinase inhibitors & 70 \\
cell survival and differentiation & inhibitors of cyclin-dependent kinases \\
neurite outgrowth & malonylginsenoside Rb1 & 62 \\
G2-M arrest & apigenin & 73 \\
staurosporin-induced apoptosis & Ginkgo biloba extract & 61 \\
\hline
\end{tabular}

proach these functions were rare. However, the recent development of multi-electrode arrays (76-78) for determination of spike generation and propagation in brain slices or in neurons cultured on these arrays (Fig. 3) has considerably improved this situation. The suitability of multi-electrode arrays for screening purposes was already demonstrated with normal drugs (77), (79), (80) and has revealed a great perspective. Another feature, excitotoxicity, is also coupled to neuron activation. There, high concentrations of excitatory neurotransmitters such as glutamate lead to cell death by apoptosis (82). In the past, single cell recording of the electrophysiological activity of the neurons was applied in such studies (83). Again, the use of multi-electrode arrays may revolutionize mechanistic studies on excitotoxicity which might play an important role in neurodegenerative diseases such as Huntington's disease. Alzheimer's disease, trauma, and many others. Although phytopharmaceuticals have not yet been tested using multi-electrode arrays, it can be expected that this new and sophisticated experimental system may considerably advance studies on neurotrophic and neuroprotective effects of plant-derived materials.

\section{General Aspects of the Screening of Plant Materials for Effects on Cultured Cells}

Plant materials under consideration for efficacy testing are usually composed of complex mixtures of different compounds with different solubility in aqueous culture media. Furthermore, inert additives may also be included. These properties render it necessary to search for appropriate incubation conditions. Some examples relevant for mixtures or compounds with different solubilities are provided in Table 3. Of course, direct contact of insoluble material with the cultured cells has to be avoided as have higher concentrations of solvents in the culture medium (e.g., exceeding $2 \%$ DMSO).

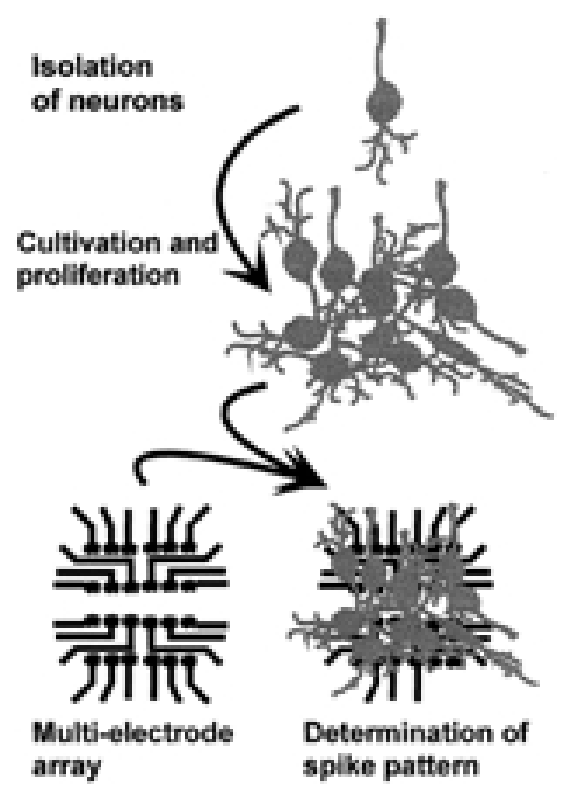

Fig. 3 Schematic illustration of the use of multi-electrode arrays for determination of neuronal spike generation and propagation. Neurons are isolated from brain tissue and cultured on multi-electrode arrays coated with appropriate substrates (77), (78). Alternatively, organ cultures of brain slices can be used (76). The multi-electrode arrays allow the simultaneous recording of spike generation by different neurons on many (e.g., 64) different channels after amplification. Using computerized analysis of the spike pattern by so-called neuronal networks it is possible to determine the influence of drugs on spontaneous or induced spike generation and propagation in a semiquantitative manner. 
Table 3 Techniques for the incubation of cultured cells with plant derived materials.

\begin{tabular}{|c|c|c|c|}
\hline Material & Solubility in water & Handling/Solubilization & Incubation technique \\
\hline \multirow[t]{4}{*}{ powdered material } & low & adsorption to filter paper & floating filter technique \\
\hline & & dispersion in culture medium & bottom chamber of transfilter well cultures \\
\hline & medium & $\begin{array}{l}\text { extraction with solvents (DMSO, alcohols, } \\
\text { hexane, etc.) }\end{array}$ & $\begin{array}{l}\text { normal incubation; special solvent controls } \\
\text { necessary: solvent alone; solvent added after } \\
\text { extraction with water }\end{array}$ \\
\hline & high & extraction with water or culture medium & normal incubation \\
\hline \multirow[t]{3}{*}{ liquid material } & low & adsorption on filter paper & floating filter technique \\
\hline & medium & addition of or extraction with solvents & $\begin{array}{l}\text { floating filter technique after evaporation of } \\
\text { solvent; normal incubation including solvent } \\
\text { controls }\end{array}$ \\
\hline & high & dilution with culture medium & normal incubation \\
\hline
\end{tabular}

This may sometimes severely limit the testing of water-insoluble material. In many cases the so-called floating filter technique may provide a (partial) solution, since excess solvent can be evaporated. If solvents are unavoidable, appropriate control incubations are of greatest importance and should include not only addition of solvent alone to the culture medium, but also to an extract obtained by another extraction procedure.

\section{Conclusions and Perspectives}

As demonstrated for hepatocytes and neuronal cells, cell culture systems provide valuable in vitro approaches for the screening of plant extracts, phytopharmaceuticals and drugs as well as for the elucidation of possible mechanisms of action on a molecular level. It is hoped that such systems may reduce animal testing considerably. However, it should be emphasized that the results do not necessarily reflect all actions that may occur in the whole organism, either in animals or in man. For instance, bioavailability remains a critical factor that must be determined in the intact organism. It may depend on different routes of administration as well as on interactions with other constituents or extract formulations. Furthermore, systemic and other complex effects may be responsible for beneficial or adverse effects not detectable by these in vitro approaches. Thus, careful clinical investigations must accompany all in vitro studies, particularly if high-dosed extracts are considered. Despite these limitations, however, the in vitro studies with intact cells may considerably advance our knowledge about the beneficial effects of phytopharmaceuticals and, in some cases, may even provide the only source by which such detailed information can be obtained.

\section{References}

${ }^{1}$ Begue JM, Guguen-Guillouzo Ch, Pasdeloup N, Guillouzo A. Prolonged maintenance of active cytochrome P-450 in adult rat hepatocytes co-cultured with another liver cell type. Hepatology 1984; 4: 839-42

${ }^{2}$ Rogiers V, Vercruysse A. Rat hepatocyte cultures and co-cultures in biotransformation studies of xenobiotics. Toxicology 1993; 82: 685-90

${ }^{3}$ Gebhardt R. Improved drug metabolizing capacity of hepatocytes co-cultured with epithelial cells and maintained in a perifusion system. Alternatives to animal testing. (Reinhardt Ch, ed.), Verlag Chemie, Weinheim, New York 1994: $141-6$
${ }^{4}$ Kern A, Bader A, Pichlmayr R, Sewing KF. Drug metabolism in hepatocyte sandwich cultures of rats and humans. Biochem. Pharmacol. 1997; 54: 761 - 72

${ }^{5}$ Gebhardt R, Wegner H, Alber J. Perfusion of cocultured hepatocytes: optimization of studies on drug metabolism and cytotoxicity in vitro. Cell. Biol. Toxicol. 1996; 12: 57-68

${ }^{6}$ Gebhardt R. Multiple inhibitory effects of garlic extracts on cholesterol biosynthesis in hepatocytes. Lipids 1993; 28: 613-9

${ }^{7}$ Gebhardt R. Amplification of palmitate-induced inhibition of cholesterol biosynthesis in cultured rat hepatocytes by garlic-derived allyl thiosulfinates. Phytomedicine 1995; 2: 29-34

${ }^{8}$ Brown AM, Baker PW, Gibbons GF. Changes in fatty acid metabolism in rat hepatocytes in response to dietary n-3 fatty acids are associated with changes in the intracellular metabolism and secretion of apolipo protein B-48. J. Lipid. Res. 1997; 38: 469-81

${ }^{9}$ Gebhardt R. Antioxidative and protective properties of extracts from leaves of the artischoke (Cynara Scolymus L.) against hydroperoxide-induced oxidative stress in cultured rat hepatocytes. Toxicol. Appl. Pharmacol. 1997; 144: 279-86

${ }^{10}$ Manzano A, Roig T, Bermudez, Bartrons R. Effects of taxol on isolated rat hepatocyte metabolism. Am. J. Physiol. 1996; 271: C1957-62

${ }^{11}$ Gebhardt R. Garlic: The key to sophisticated lowering of hepatocellular lipid. Nutrition 1997; 13: 379-80

${ }^{12}$ Li JX, Shi Q Xiong QB, Prasain JK, Tezuka Y, Hareyama T et al. Tribulusamide $A$ and $B$, new hepatoprotective lignanamides from the fruits of Tribulus terrestris: indications of cytoprotective activity in murine hepatocyte culture. Planta Med. 1998; 64: 628-31

${ }^{13}$ Romiti N, Tongiani R, Cervelli F, Chieli E. Effects of curcumin on Pglycoprotein in primary cultures of rat hepatocytes. Life Sci. 1998; 62: $2349-58$

${ }^{14} \mathrm{Li}$ AP, Jurima-Romet M. Application of primary human hepatocytes in the evaluation of pharmacokinetic drug-drug interactions: evaluation of model drugs terfenadine and rifampin. Cell Biol. Toxicol. 1997; 365-74

${ }^{15}$ Song LL, Kosmeder JW 2nd, Lee SK, Gerhauser C, Lantvit D, Moon RC, Moriarty RM, Pezzuto JM. Cancer chemopreventive activity mediated by 4 '-bromoflavone, a potent inducer of phase II detoxification enzymes. Cancer Res. 1999; 59: 578-85

${ }^{16}$ Gebhardt R. Use of isolated and cultured hepatocytes in studies on bile formation. Isolated and cultured hepatocytes. (Guillouzo A, Guguen-Guillouzo C, eds.), INSERM, Paris and John Libbey, London 1986: pp. 353-76

${ }^{17}$ Petzinger E. Transport of organic anions in the liver. Rev. Physiol. Biochem. Pharmacol. 1994; 123: 47-211

${ }^{18}$ Burger HJ, Gebhardt R, Mayer C, Mecke D. Different capacities for amino acid transport in periportal and perivenous hepatocytes isolated by digitonin/collagenase perfusion. Hepatology 1989; 9: $22-8$ 
19 Boyer JL, Gautham A, Graf J. Mechanisms of bile secretion: insights from the isolated rat hepatocyte couplet. Semin. Liver Dis. 1998; 8: $308-16$

${ }^{20}$ Gebhardt R, Jung W. Biliary secretion of sodium fluorescein in primary cultures of adult rat hepatocytes and its stimulation by nicotinamide. J. Cell Sci. 1982; 56: 233-44

${ }^{21}$ Jung W, Gebhardt R, Robenek H. Primary cultures of rat hepatocytes as a model system of canalicular development, biliary secretion, and intrahepatic cholestasis. II. Taurolithocholate-induced alterations of canalicular morphology and of the distribution of filipin-cholesterol complexes. Eur. J. Cell Biol. 1982; 29: 77-82

${ }^{22}$ Gebhardt R. Extrakte und Inhaltsstoffe aus Blättern der Artischocke (Cynara scolymus L.) verhindern die Traurolithocholat-induzierte Transformation kanalikulärer Membranen. Z. Gastroenterol. 1999; 37: 74

${ }^{23}$ Lekehal M, Pessayre D, Lereau JM, Moulis C, Fouraste I, Fau D. Hepatotoxicity of the herbal medicine germander: metabolic activation of its furano diterpenoids by cytochrome P450 3A depletes cytoskeleton-associated protein thiols and forms plasma membrane blebs in rat hepatocytes. Hepatology 1996; 24: $212-8$

${ }^{24}$ Gordon PB, Holen I, Seglen PO. Protection by naringenin and some other flavonoids of hepatocytic autophagy and endocytosis against inhibition by okadaic acid. J. Biol. Chem. 1995; 270 $5830-8$

${ }^{25}$ Kosina P, Dvorak ZD. The human hepatocyte: I. A model for studying metabolism and toxicity of xenobiotics. Ceska. Slov. Farm. 1999; 48: $65-71$

${ }^{26}$ Guillouzo A, Morel F, Langouet S, Maheo K, Rissel M. Use of hepatocyte cultures for the study of hepatotoxic compounds. J. Hepatol. 1997; 26: 73-80

${ }^{27}$ Gebhardt R, Fausel M. Antioxidant and hepatoprotective effects of artichoke extracts and constituents in cultured rat hepatocytes. Toxicol. In vitro 1997; $11: 669-72$

${ }^{28}$ Gebhardt RJ. Inhibition of cholesterol biosynthesis in primary cultured rat hepatocytes by artichoke (Cynara scolymus L.) extracts. Pharmacol. Exp. Therap. 1998; 286: 1122-8

${ }^{29}$ Paine AJ. The maintenance of cytochrome P-450 in rat hepatocyte culture: some applications of liver cell cultures to the study of drug metabolism, toxicity and the induction of the P-450 system. Chem. Biol. Interact. 1990; 74: 1- 31

${ }^{30}$ Guillouzo A. Liver cell models in in vitro toxicology. Environ. Health. Perspect 1998; 106: $511-32$

${ }^{31}$ Gebhardt R, Lippert C, Schneider A, Doehmer J. Improved determination of drug metabolism by perifusion of recombinant V79 cells carrying human CYP3A4. Toxicol. In vitro 1999; 13: 639-43

32 Morel I, Sergent O, Cogrel P, Lescoat G, Pasdeloup N, Brissot P, Cillard P, Cillard J. EPR study of antioxidant activity of the iron chelators pyoverdin and hydroxypyrid-4-one in iron-loaded hepatocyte culture: comparison with that of desferrioxamine. Free Radic. Biol. Med. 1995; 18: 303 - 10

${ }^{33}$ Sergent O, Griffon B, Morel I, Chevanne M, Dubos MP, Cillard P, Cillard J. Effect of nitric oxide on iron-mediated oxidative stress in primary rat hepatocyte culture. Heptology 1997; 25: $122-7$

${ }^{34}$ Morel I, Abalea V, Sergent O, Cillard P, Cillard J. Involvement of phenoxyl radical intermediates in lipid antioxidant action of myricetin in iron-treated rat hepatocyte culture. Biochem. Pharmacol. 1998; 55: 1399-404

${ }^{35}$ Croft KD. The chemistry and biological effects of flavonoids and phenolic acids. Ann. N. Y. Acad. Sci. 1998; 854: 435-42

${ }^{36}$ Gebhardt R, Rexhepaj R, Fausel M. Antioxidative und hepatoprotektive Wirkung von Flavonoiden aus Blattextrakten der Artischocke. Z. Phytother. 1999; 20: 97-8

${ }^{37}$ Kawada N, Seki S, Inoue M, Kuroki T. Effect of antioxidants, resveratrol, quercetin, and $\mathrm{N}$-acetylcysteine, on the functions of cultured rat hepatic stellate cells and Kupffer cells. Hepatology 1998; 27: $1265-74$
${ }^{38}$ Cao G, Sofic E, Prior RL. Antioxidant and pro-oxidant behaviour of flavonoids: structure-activity relationships. Free. Radical Biol. Med. 1997; 22: 749-60

${ }^{39}$ Morel I, Lescoat G, Cillard P, Cillard J. Role of flavonoids and iron chelation in antioxidant action. Methods Enzymol. 1994; 234: 437-43

${ }^{40}$ Morel I, Lescoat G, Cogrel P, Sergent O, Pasdeloup N, Brissot P, Cillard P, Cillard J. Antioxidant and iron-chelating activities of the flavonoids catechin, quercetin and diosmetin on iron-loaded rat hepatocyte cultures. Biochem. Pharmacol. 1993; 45: 13-9

${ }^{41}$ Musonda CA, Chipman JK. Quercetin inhibits hydrogen peroxide $\left(\mathrm{H}_{2} \mathrm{O}_{2}\right)$-induced NF-kappaB DNA binding activity and DNA damage in HepG2 cells. Carcinogenesis 1998; 19: 1583-9

42 Diel P, Smolnikar K, Michna H. In vitro test systems for the evaluation of the estrogenic activity of natural products. Planta Med. 1999; 65: $197-203$

${ }^{43}$ Pelissero C, Flouriot G, Foucher J, Bennetau B, Dunogues J, Le Gac F, Sumpter JP. Vitellogenin synthesis in cultured hepatocytes; an in vitro test for the estrogenic potency of chemicals. J. Steroid Biochem. Mol. Biol. 1993; 44: 263-72

${ }^{44}$ Akiyama T, Ishida J, Nakagawa S, Ogawara H, Watanabe S, Itoh N, Shibuya M, Fukami Y. Genistein, a specific inhibitor of tyrosinespecific protein kinases. J. Biol. Chem. 1987; 262: $5592-5$

${ }^{45}$ Jinsart W, Ternai B, Polya GM. Inhibition of rat liver cyclic AMPdependent protein kinase by flavonoids. Biol. Chem. Hoppe Seyler 1992; 373: $205-11$

${ }^{46}$ Kuo M-L, Yang N-C. Reversion of v-H-ras-transformed NIH 3T3 cells by apigenin through inhibiting mitogen activated protein kinase and its downstream oncogenes. Biochem. Biophys. Res. Commun. 1995; 221: 767-75

${ }^{47}$ Auer KL, Spector MS, Tombes RM, Seth P, Fisher PB, Gao B et al. Alpha-adrenergic inhibition of proliferation in HepG2 cells stably transfected with the alpha1B-adrenergic receptor through a p42MAPkinase/p21Cip1/WAF1-dependent pathway. FEBS Lett. 1998; 436: $131-8$

${ }^{48}$ Borradaile NM, Carroll KK, Kurowska EM. Regulation of HepG2 cell apolipoprotein B metabolism by the citrus flavanones hesperetin and naringenin. Lipids 1999; 34: $591-8$

${ }^{49}$ Sliou C, Rihn B, Cillard J, Okamoto T, Packer L. Selective inhibition of NF-kappaB activation by the flavonoid hepatoprotector silymarin in HepG2. Evidence for different activating pathways. FEBS Lett. 1998; 440: $8-12$

${ }^{50}$ Duthie SJ, Johnson W, Dobson VL. The effect of dietary flavonoids on DNA damage (strand breaks and oxidised pyrimidines) and growth in human cells. Mutat. Res. 1997; 390: $141-51$

51 Gebhardt R. Altered acinar distribution of glutamine synthetase and different growth response of cultured enzyme-positive and -negative hepatocytes after partial hepatectomy. Cancer Res. 1990; 50: 4407-10

52 Volk A, Michalopoulos G, Weidner M, Gebhardt R. Different proliferative response of periportal and pericentral rat hepatocytes to hepatocyte growth factor. Biochem. Biophys. Res. Commun. 1995; 207: $578-84$

${ }^{53}$ Leist M, Gantner F, Künstle G, Wendel A. Cytokine-mediated hepatic apoptosis. Rev. Physiol. Biochem. Pharmacol. 1998; 133: 109-55

${ }^{54}$ Leist M, Nicotera P. The shape of cell death. Biochem. Biophys. Res. Commun. 1997; 236: 1-9

${ }^{55}$ Gebhardt R, Hartung T. Cokulturen in der in vitro-Toxikologie. Biospektrum 1996; 2: 36-9

${ }^{56}$ Middleton EJr. Effects of plant flavonoids on immune and inflammatory cell function. Adv. Exp. Med. Biol. 1998; 439: 175-82

${ }^{57}$ Gebhardt R. Oxidative stress, antioxidants and liver fibrosis. Phytomedicine 2000; in press

${ }^{58}$ Chan MM, Fong D, Ho CT, Huang HI. Inhibition of inducible nitric oxide synthase gene expression and enzyme activity by epigallocatechin gallate, a natural product from green tea. Biochem. Pharmacol. 1997; 54: $1281-6$ 
${ }^{59}$ Sparapani M, Buonamici L, Ciani E, Battelli MG, Ceccarelli G, Stirpe $\mathrm{F}$ et al. Toxicity of ricin and volkensin, two ribosome-inactivating proteins, to microglia, astrocyte, and neuron cultures. Glia 1997; 20: $203-9$

${ }^{60}$ Lee J, Bruce-Keller AJ, Kruman Y, Chan SL, Mattson MP. 2-DeoxyD-glucose protects hippocampal neurons against excitotoxic and oxidative injury: evidence for the involvement of stress proteins. J. Neurosci. Res. 1999; 57: 48-61

${ }^{61}$ Sato F, Matsukawa Y, Matsumoto K, Nishino H, Sakai T. Apigenin induces morphological differentiation and G2-M arrest in rat neuronal cells. Biochem. Biophys. Res. Commun. 1994; 204: 578-84

62 Park DS, Farinelli SE, Greene LA. Inhibitors of cyclin-dependent kinases promote survival of post-mitotic neuronally differentiated PC12 cells and sympathetic neurons. J. Biol. Chem. 1996; 271: $8161-9$

${ }^{63}$ Ahlemeyer B, Mowes A, Krieglstein J. Inhibition of serum deprivation- and staurosporine-induced neuronal apoptosis by Ginkgo biloba extract and some of its constituents. Eur. J. Pharmacol. 1999; 367: $423-30$

${ }^{64}$ Neary JT, Bu Y, Hypericum LI 160 inhibits uptake of serotonin and norepinephrine in astrocytes. Brain Res. 1999; 816: 358-63

${ }^{65}$ Fenart L, Buee-Scherrer V, Descamps L, Duhem C, Poullain MG, Cecchelli $R$ et al. Inhibition of P-glycoprotein: rapid assessment of its implication in blood-brain barrier integrity and drug transport to the brain by an in vitro model of the blood-brain barrier. Pharma. Res. 1998; 15: $993-1000$

${ }^{66}$ Kyo R, Nakahata N, Sakakibara I, Kubo M, Ohizumi Y. Baicalin and baicalein, constituents of an important medicinal plant, inhibit intracellular $\mathrm{Ca}^{2+}$ elevation by reducing phospholipase $\mathrm{C}$ activity in C6 rat glioma cells. J. Pharm. Pharmacol. 1998; 50: 1179-82

${ }^{67}$ Soliman KF, Mazzio EA. In vitro attenuation of nitric oxide production in C6 astrocyte cell culture by various dietary compounds. Proc. Soc. Exp. Biol. Med. 1998; 218: 390-97

${ }^{68}$ Kyo R, Nakahata N, Sakakibara I, Kubo M, Ohizumi Y. Effects of Sho-saiko-to, San'o-shashin-to and Scutellariae Radix on intracellular $\mathrm{Ca}^{2+}$ mobilization in $\mathrm{C} 6$ rat glioma cells. Biol. Pharm. Bull. 1998; 21: 1067-71

${ }^{69}$ Mattson MP, Barger SW, Begley JG, Mark RJ. Calcium, free radicals, and excitotoxic neuronal death in primary cell culture. Methods Cell. Biol. 1995; 46: 187-216

${ }^{70}$ Marra B, Alessandrini A, Cole AJ, Yee AG, Furshpan EJ. Inhibition of the p44/42 MAP kinase pathway protects hippocampal neurons in a cell-culture model of seizure activity. Proc. Natl. Acad. Sci. USA 1998; 95: 11975-80

${ }^{71}$ Rogers DC, Hunter AJ. Dissociation of effects of glutamate receptor antagonists on excitotoxic and hypoxic neuronal cell death in a novel rat cortical culture system. Brain. Res. Bull. 1997; 44: $131-9$

72 Mohri T, Chiba K, Yamazaki M, Shimizu M, Morita N. Activation of PC12 cells by lipophilic components of Panax ginseng. Planta Med. 1992; 58: $321-3$

${ }^{73}$ Nishiyama N, Cho SI, Kitagawa I, Saito H. Malonylginsenoside Rb1 potentiates nerve growth factor (NGF)-induced neurite outgrowth of culture chick embryonic dorsal root ganglia. Biol. Pharm. Bull. 1994; 17: 509-13

${ }^{74}$ English DS, Doyle RT, Petrich JW, Haydon PG. Subcellular distributions and excited-state processes of hypericin in neurons. Photochem. Photobiol. 1999; 69: 301 -5

${ }^{75}$ Robles M, Wang N, Kim R, Choi BH. Cytotoxic effects of repin, a principal sesquiterpene lactone of Russian knapweed. J. Neurosci. Res. 1997; 47: 90-7

${ }^{76}$ Fennrich St, Stier H, Föhr K-J, Ray D, Ghersi-Egea J-F, Schlosshauer B. Organotypic rat brain culture as in vitro-like model system. Methods in Cell Science 1996; 18: 283-91

${ }^{77}$ Gopal KV, Gross GW. Auditory cortical neurons in vitro: initial pharmacological studies. Acta Otolarymgol 1996; 116: 697-704
${ }^{78}$ Egert U, Schlosshauer B, Fennrich W, Nisch W, Fejtl M, Knott T et al. A novel organotypic long-term culture of the rat hippocampus on substrate-integrated multielectrode arrays. Brain Research Protocols 1998; 2: 229-42

${ }^{79}$ Gross GW, Harsch A, Rhoades BK, Göpel W. Odor, drug and toxin analysis with neuronal networks in vitro: extracellular array recording of network responses. Biosens. Bioelectron 1997; 12: $373-93$

${ }^{80}$ Harsch A, Ziegler C, Göpel W. Strychnine analysis with neuronal networks in vitro: extracellular array recording of network responses. Biosens. Bioelectron 1997; 12: 827-35

81 Williams GM. Review of in vitro test systems using DNA damage and repair for screening of chemical carcinogens. J. Assoc Off. Anal. Chem. 1979; 62: 857-63

${ }^{82}$ Leist M, Nicotera P. Apoptosis, excitotoxicity, and neuropathology. Exp. Cell Res. 1998; 239: 183-201

${ }^{83}$ Huettner JE, Baugham RW. Primary culture of identified neurons from the visual cortex of postnatal rats. J. Neurosci. 1986; 6: $3044-60$

\section{Prof. Dr. Rolf Gebhardt}

Institut für Biochemie

Universität Leipzig

Liebigstr. 16

04103 Leipzig

Germany

E-mail: rgebhardt@medizin-uni-leipzig.de

Fax: +49-341-9722109

Tel. +49-341-9722100 